Arq. Bras. Med. Vet. Zootec., v.63, n.2, p.326-332, 2011

\title{
Morfologia do útero de cutias nulíparas e não nulíparas
}

[Morphology of the uterus of nulliparous and non nulliparous agoutis]

L.L. Martins, M.M. Biagioni, F.S. Oliveira, G.H. Toniollo, M.R. Pacheco, M.R.F. Machado

FCAV/UNESP

Via de Acesso Prof.Paulo Donato Castellane s/n

14884-900 - Jaboticabal, SP

\begin{abstract}
RESUMO
Descreveu-se a morfologia do útero de cutias nulíparas e não nulíparas por meio de ovariossalpingoisterectomia. A análise macroscópica do útero foi realizada in loco e na peça retirada. Segmentos das porções proximal, média e distal do órgão foram colhidas, fixadas e preparadas histologicamente, sendo as amostras analisadas à microscopia de luz, e realizada a histomorfometria das camadas uterinas. Topograficamente, o útero localiza-se na região sublombar, caudalmente aos rins, em continuação aos ovários e às tubas uterinas, estendendo-se até à entrada da pelve, onde se posiciona dorsalmente à bexiga. Caracteriza-se como do tipo duplo, embora culmine em apenas um óstio cervical externo. Microscopicamente, a mucosa uterina é formada por variações do epitélio, de cilíndrico a pseudoestratificado, que se apoia em tecido conjuntivo frouxo, onde se observam glândulas endometriais revestidas por epitélio cilíndrico, além da presença de vasos sanguíneos. A camada muscular subdivide-se em interna ou submucosa, média ou vascular e externa ou subserosa. A camada serosa é composta por tecido conjuntivo e mesotélio. Na histomorfometria, verificou-se que a espessura uterina total e a espessura da camada mucosa, em média, foram maiores nas fêmeas não nulíparas.
\end{abstract}

Palavras-chave: Dasyprocta azare, roedor, histricomorfo, anatomia, histologia

\begin{abstract}
The uterine morphology was studied through ovarysalpingohysterectomy in nulliparous and non nulliparous agoutis (Dasyprocta azare). The uterus macroscopic analysis was done "in loco" and in the removed specimens. Fragments of the proximal, media and distal portions of this viscerae were collected, fixed and histologically prepared, and the samples analyzed through light microscopy and through the histomorphometry of the uterine layers. Topographycally, the uterus of this rodent is located on the sub lumbar area, caudally to the kidneys, and following the ovaries and uterine horns, getting through the pelvic entrance, where it is located dorsally to the bladder. It is characterized as a double uterus, although there is only an external cervical os. Microscopically, the uterine mucous is formed by epithelial elevations, from cylindrical to pseudostratified epithelium, which is supported by a loose connective tissue where endometrial glands covered by cylindrical epithelium can be observed, besides blood vessels. The muscle layer is subdivided in inner or submuscous, median or vascular and outer or subserous. The serous layer is composed of a connective tissue and mesothelium. In the histomorphometry analysis, the total uterine thickness and the mucous layer thickness, in average, were bigger on non nulliparous females.
\end{abstract}

Keywords: Dasyprocta azare, rodent, hystricomorph, anatomy, histology

Recebido em 18 de março de 2010

Aceito em 21 de março de 2011

E-mail:lmartins321@gmail.com 


\section{INTRODUÇÃo}

A cutia (Dasyprocta azarae), roedor da família Dasyproctidae, pesa entre 1,5 e 2,8kg e alimentase de folhas, raízes, flores, fungos, sementes e, especialmente, de frutos caídos no solo (Chaves e Santos, 2005; Lange e Schmidt, 2007).

Em muitos roedores, o útero consiste em tubos pares que se abrem separadamente na vagina, e é denominado útero duplo ou duplex (Dyce et al., 2004). A rata (Greene, 1955; Smallwood, 1992; Gray et al., 2001) e a coelha (Praag, 2003) apresentam útero duplo, contínuo ao seu próprio canal cervical, e vagina simples. Nas ratas de laboratório (Rattus norvegicus), há dois canais cervicais distintos (Cooper e Schiller, 1975; Besselsen, 2003), e, na fêmea do camundongo (Mus musculus), o canal cervical é simples, e o útero bicórneo (Greene, 1955; Smallwood, 1992; Gray et al., 2001).

As capivaras (Hydrochoreus hydrochaeris) (Ojasti, 1973), assim como o castor (Myocastor coypus) (Felipe et al., 1998), apresentam útero duplex, embora na capivara os cornos estejam interligados por duas aberturas craniais da cérvix, as quais se fundem em uma única abertura caudal, que se comunica com a vagina (Ojasti, 1973). O útero da paca (Agouti paca) é bicórnico, e os cornos uterinos estão unidos externamente por meio de uma membrana delgada, formando um falso corpo (Matamoros, 1981). As cutias apresentam útero duplo formado por dois cornos, uma cérvix com dois orifícios distintos que se comunicam com o corpo, além de um canal único que se liga à vagina (Guimarães, 1993). Araujo et al. (2002) citaram que, nesses animais, o útero não deveria ser classificado como duplo, mas não propuseram outra classificação. Para Moura et al. (2003), o corpo uterino da cutia é pequeno, envolvido por uma membrana única externa e internamente separado por um septo espesso, formando dois canais que desembocam isoladamente na cérvix, a qual apresenta dois orifícios craniais e um caudal. Dessa forma, no útero duplo parcial da cutia, há dois cornos, um falso corpo e uma cérvix com dupla abertura cranial, além de um canal único ligando-a à vagina.

Quanto aos aspectos microscópicos do útero, nas espécies domésticas, este órgão possui as camadas serosa, muscular e mucosa, conhecidas, respectivamente, como perimétrio, miométrio e endométrio. A camada serosa atinge o útero por extensão do ligamento largo de suporte. O músculo está arranjado em camadas - a longitudinal, externa delgada, e a circular interna mais espessa -, separadas por um estrato bastante vascularizado de tecido conjuntivo (Schwarze e Schröder, 1970; Nickel et al., 1979; Dellmann e Brown, 1982; Banks, 1992; Dyce et al., 2004; König e Liebich, 2004). O endométrio é espesso, e seu relevo superficial varia entre as espécies; inúmeras glândulas tubulares abrem-se em sua superfície, e o epitélio apresenta-se, geralmente, colunar simples (Dyce et al., 2004).

O endométrio é constituído por epitélio superficial, simples cilíndrico na égua e na cadela. Na porca e nos ruminantes, é pseudoestratificado cilíndrico, e, em áreas isoladas, o epitélio pode ser cúbico. A camada superficial da lâmina própria submucosa consiste em tecido conjuntivo frouxo ricamente vascularizado. Glândulas simples, tubulares ramificadas espiraladas, revestidas de epitélio simples cilíndrico ciliado e não ciliado, estão presentes por todo o endométrio, exceto nas áreas de carúnculas dos ruminantes. A ramificação e o espiralamento das glândulas são extensos na égua, enquanto se observa menor ramificação nos carnívoros (Dellmann e Brown, 1982; Banks, 1992).

O miométrio consiste em uma espessa camada circular interna e uma camada longitudinal externa de células musculares lisas, que aumentam de número e tamanho durante a gravidez; entre as duas camadas, ou profundamente na camada interna, há uma zona vascular constituída de grandes artérias, veias e vasos linfáticos (Dellmann e Brown, 1982).

O perimétrio consiste em tecido conjuntivo frouxo coberto pelo mesotélio peritoneal. Possui células musculares lisas e numerosos vasos linfáticos e sanguíneos, além de fibras nervosas (Dellmann e Brown, 1982). Para Gartner e Hiatt (1999) e Junqueira e Carneiro (2008), no útero da mulher, o perimétrio pode ser constituído de adventícia ou serosa.

Considerando-se que são escassos os trabalhos que detalharam a morfologia do aparelho reprodutivo da cutia, este trabalho teve o objetivo 
de descrever a morfologia uterina de cutias nulíparas e não nulíparas.

\section{MATERIAL E MÉTODOS}

Esta pesquisa foi aprovada pela Comissão de Ética e Bem-Estar Animal (CEBEA) da FCAV, campus de Jaboticabal, UNESP, protocolo $\mathrm{n}^{\circ}$ 008581-07, de acordo com os Princípios Éticos na Experimentação Animal, adotados pelo Colégio Brasileiro de Experimentação Animal (COBEA). Foram utilizadas oito cutias fêmeas, quatro delas nulíparas e quatro não nulíparas, adultas, com média de peso de $2,57 \pm 0,44 \mathrm{~kg}$, pertencentes ao Zoológico Municipal Missina Palmeira Zancaner, do município de Catanduva, SP, alojadas em conjunto, sob manejo semilivre e alimentadas por folhas, legumes e raízes. Analisou-se também o útero de uma peça anatômica de cutia adulta, na qual o útero apresentava-se in loco.

Os úteros foram analisados macroscopicamente quanto à forma e posição, durante a ovariossalpingoisterectomia a que as cutias foram submetidas. Essa análise também foi feita em uma peça anatômica de um animal, que foi acessada mediante a abertura da cavidade abdominal e cuidadosa dissecção para a retirada das vísceras e preservação dos ovários, da tuba uterina e do útero in loco.

Foram retirados fragmentos das porções proximal, média e distal dos cornos uterinos, os quais foram fixados em solução de Bouin e incluídos em paraplast (Histosec ${ }^{\circledR}$ - Merck). Os cortes de $5 \mu \mathrm{m}$ foram corados com hematoxilinaeosina e tricrômio de Masson. Outros fragmentos foram fixados em solução de McDowel e incluídos em historesina (Historesin ${ }^{\circledR}$ Leica/Germany), e os cortes, de 1 a $3 \mu \mathrm{m}$, corados com hematoxilina-phloxina $\mathrm{B}$ e azul de toluidina a $1 \%$ e $0,5 \%$. As preparações histológicas foram analisadas, e imagens capturadas em fotomicroscópio (Leica, DM5000 B) acoplado à câmara digital (Leica DFC300 FX) o foram para a documentação. Foram mensurados o conjunto de todas as camadas uterinas e a camada mucosa, isoladamente, a partir das preparações em historresina (coradas em hematoxilina-phloxina, aumento de 5x), da região média dos cornos uterinos ("Leica Application Suite - LAS” e microscópio Leica, DM5000 B).

\section{RESULTADOS E DISCUSSÃO}

O útero da cutia, similar ao das espécies domésticas e dos roedores (Schwarze e Schröder, 1970; Nickel et al., 1979; Dyce et al., 2004; König e Liebich, 2004), localiza-se na região sublombar, caudalmente aos rins, em continuação aos ovários e às tubas uterinas, estendendo-se até a entrada da pelve, onde se posiciona dorsalmente à bexiga (Fig. 1). É um órgão duplo parcial, no qual se verificam dois cornos uterinos, cuja parede de separação se torna incompleta em sua porção caudal, culminando em apenas um óstio cervical externo, embora apresente dois óstios cervicais internos e uma única vagina (Fig. 2), diferentemente de muitos roedores que apresentam útero duplo completo, como as fêmeas de rato (Smallwood, 1992; Besselsen, 2003; Dyce et al., 2004), de coelho (Smallwood, 1992; Praag, 2003), de castor (Felipe et al., 1998) e de hamster (Besselsen, 2003). Nesta última espécie, o útero é considerado bicórneo (Smallwood, 1992), tal qual a classificação atribuída ao útero de fêmeas domésticas (Schwarze e Schröder, 1970; Nickel et al., 1979; Dyce et al., 2004; Kónig e Liebich, 2004), ao de cobaias (Cooper e Schiller, 1975; Besselsen, 2003) e ao de pacas (Matamoros, 1981).

O útero duplo parcial observado é semelhante ao relatado por Ojasti (1973) na capivara, e por Moura et al. (2003) na cutia. Entretanto, distingue-se da descrição feita por Guimarães (1993), que classificou o útero da cutia como duplo, e se diferencia, ainda, das observações realizadas por Besselsen (2003) para o hamster e para o rato. Araujo et al. (2002) descreveram que o útero da cutia não deveria ser classificado como duplo, contudo não propuseram outra classificação para esse órgão. 


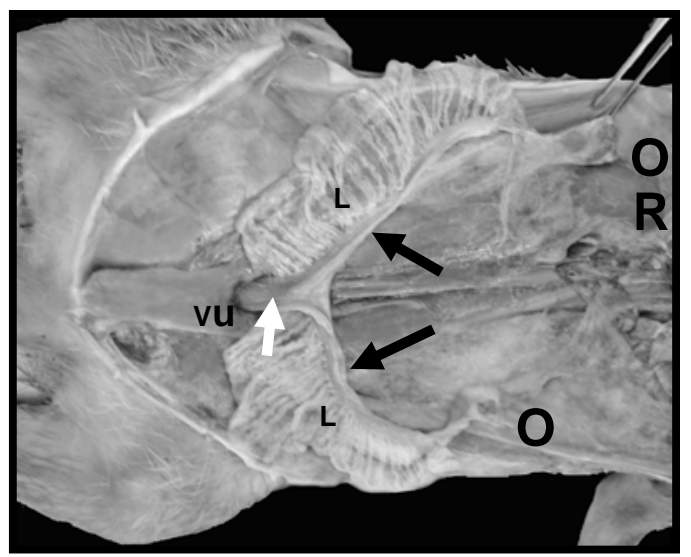

Figura 1. Fotografia da peça anatômica de uma cutia, mostrando a topografia de parte de seus órgãos urogenitais na cavidade abdominal. Observar: ovários $(\mathbf{O})$, cornos uterinos (setas pretas), corpo uterino (seta branca), rim direito (R), vesícula urinária (Vu) e o extenso ligamento largo do útero (l).

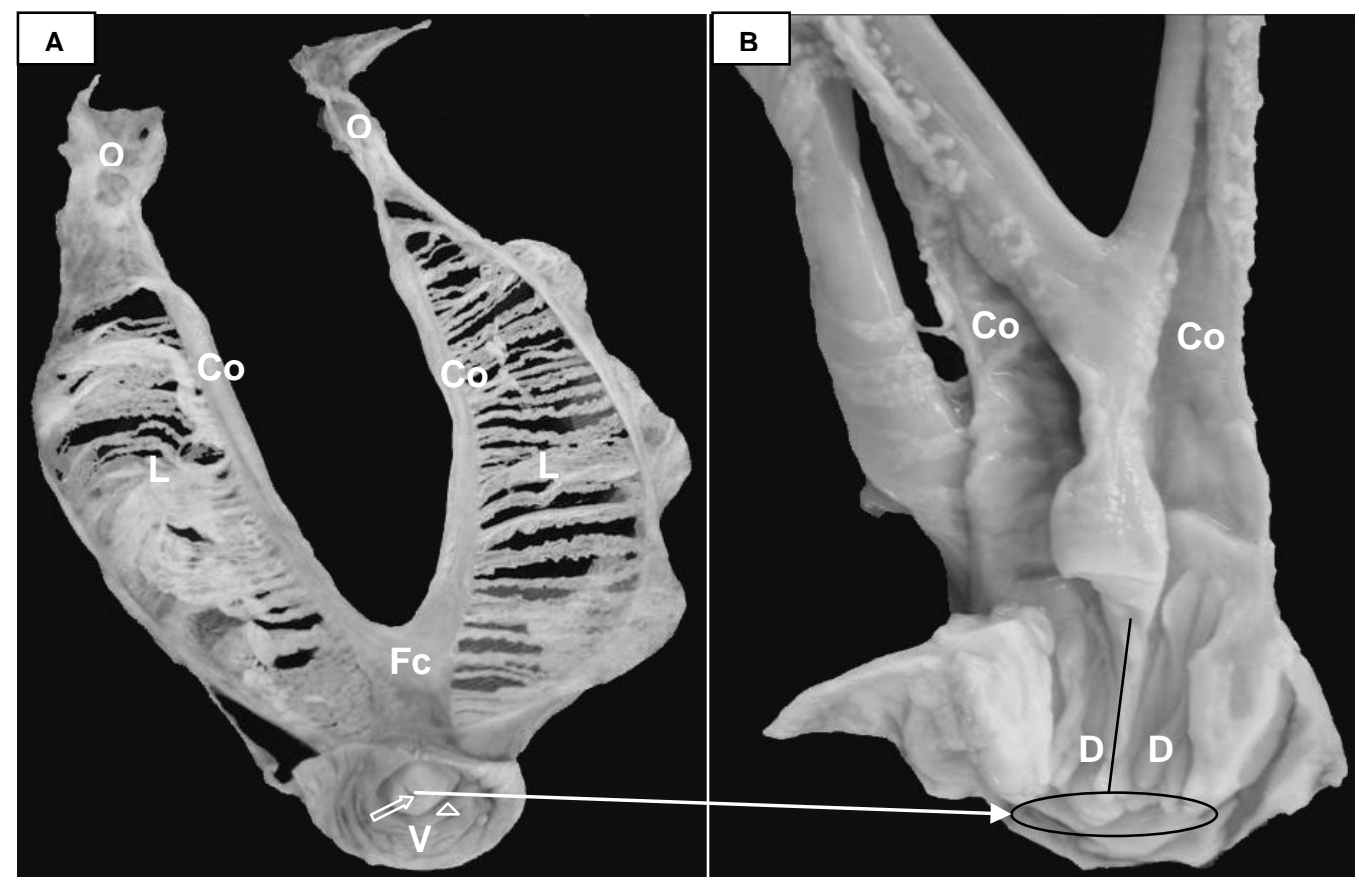

Figura 2. A: Fotografia de parte do conjunto dos órgãos genitais de cutia adulta, isolado da peça anatômica. Observar: ovários (O), cornos uterinos (Co), região do falso corpo (FC), ligamentos largos do útero $(\mathrm{L})$, cérvix $(\mathbf{C})$ projetando-se como uma papila no fórnix vaginal $(\Delta)$ com um único óstio cervical externo (seta vasada), além da porção inicial da vagina (V). B: Fotografia de parte do conjunto dos órgãos genitais de cutia adulta, com destaque para os cornos uterinos seccionados (Co), para a parede incompleta de separação entre eles, culminando em um único óstio cervical externo (círculo) e para a dupla abertura da cérvix (D), região do falso corpo do útero - corno uterino incompleto

Microscopicamente verifica-se a presença de vasos sanguíneos e de mucosa formada por epitélio simples, variando de cilíndrico baixo a cilíndrico, ou pseudoestratificado cilíndrico, apoiado em tecido conjuntivo frouxo bastante celular e com glândulas endometriais revestidas por epitélio cilíndrico (Fig. 3). Tais características assemelham-se tanto às do útero da égua e cadela, nas quais o epitélio uterino apresenta-se como simples cilíndrico, quanto ao 
do útero da porca e ruminante, em que o epitélio uterino pode ser simples cilíndrico ou pseudoestratificado cilíndrico (Dellmann e Brown, 1982; Banks, 1992). Na mulher, a mucosa uterina compõe-se de epitélio cilíndrico simples (Gartner, 1999; Junqueira e Carneiro,
2008). O epitélio uterino do porco-espinho apresenta-se pseudoestratificado colunar (Mayor et al., 2002) e o do cateto, monoestratificado colunar (Mayor et al., 2004), ambos se assemelhando, em parte, ao da cutia.

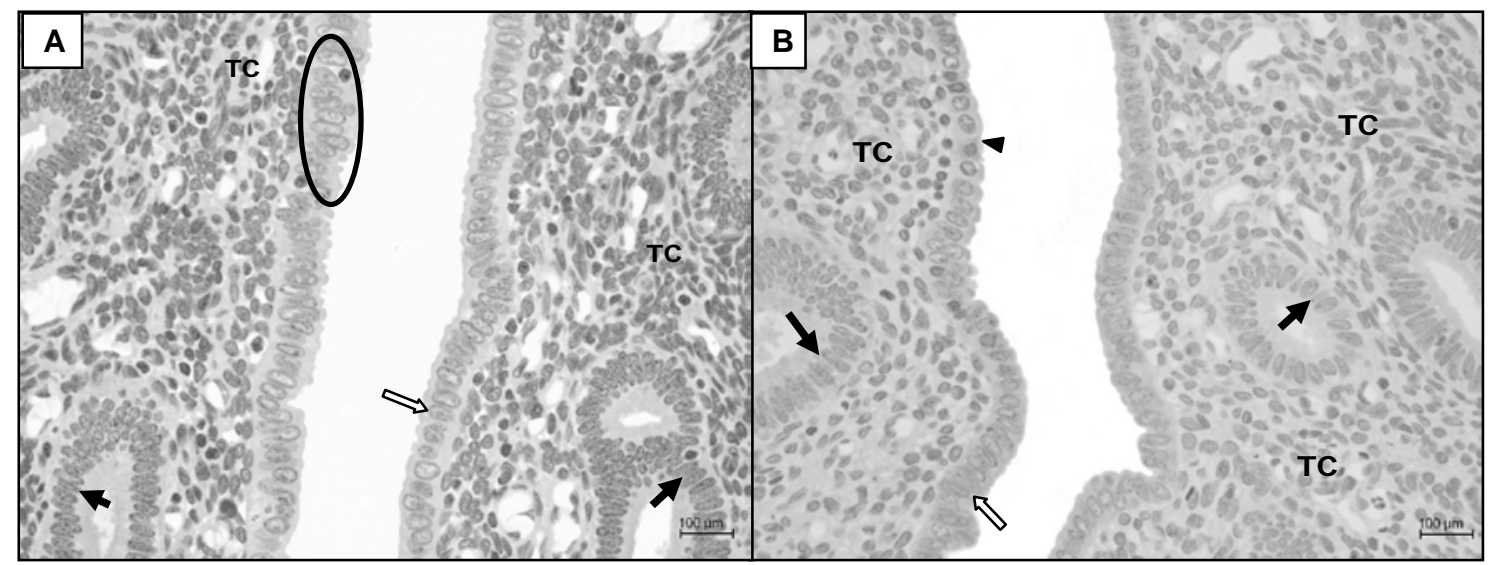

Figura 3. Fotomicrografias do útero de cutias adultas nulíparas (A) - Coloração hematoxilina-phloxina 40X - e não nulíparas (B) - coloração azul de toluidina, 40X -, mostrando em detalhe as variações do epitélio da mucosa. Observar: epitélio cilíndrico baixo ( $(\mathbf{)})$, epitélio cilíndrico (setas vazadas) e epitélio pseudoestratificado (elipse), apoiados em tecido conjuntivo frouxo bastante celular (TC). presença de glândulas endometriais revestidas por epitélio cilíndrico (setas pretas).

Verificaram-se, por toda a superfície da mucosa uterina, glândulas tubulares simples, tal qual ocorre nas espécies domésticas (Dyce et al., 2004; König e Liebich, 2004), na paca (Matamoros, 1981), no castor (Felipe et al., 1998), em ratos e camundongos (Gray et al., 2001), no porco-espinho (Mayor et al., 2002) e no cateto (Mayor et al., 2004). Embora o epitélio uterino da cutia assemelhe-se ao da paca, não se verificou, na primeira, a presença de grandes pregas ramificadas na mucosa (Matamoros, 1981).

O tecido conjuntivo, que constitui a mucosa uterina de cutias, apresentou-se bastante celular, similarmente ao que ocorre na mulher (Gartner e Hiatt, 1999; Junqueira e Carneiro, 2008).

Verificou-se que a camada muscular do útero de cutias, nulíparas e não nulíparas, é similar à descrita para os animais domésticos (Dellmann e Brown, 1982; König e Liebich, 2004) e para a paca (Matamoros, 1981). É formada por músculo liso e subdividida em camada interna circular ou submucosa, estrato vascular, que é composto por tecido conjuntivo com grande quantidade de vasos sanguíneos e linfáticos, e camada externa ou subserosa, longitudinal. Gartner e Hiatt (1999) e Junqueira e Carneiro (2008) verificaram que o miométrio da mulher é composto por três camadas de músculo liso, sendo a interna e a externa formadas de músculo liso longitudinal, e a camada média, ricamente vascularizada, de feixes de músculo liso arranjado circularmente.

A camada serosa em cutias nulíparas e não nulíparas, paca (Matamoros, 1981) e em animais domésticos (König e Liebich, 2004) apresenta-se de forma característica, constituindo-se de tecido conjuntivo frouxo coberto pelo mesotélio peritonial. Apenas na mulher o útero apresentase inclinado anteriormente e posicionado contra a bexiga, ou seja, grande parte da porção anterior desse órgão está em área retroperitoneal e, dessa forma, é revestida por adventícia, isto é, por tecido conjuntivo sem cobertura epitelial (Junqueira e Carneiro, 2008).

Quanto à histomorfometria uterina da cutia, tanto o valor médio da espessura uterina total quanto o da espessura da camada mucosa foram maiores nas não nulíparas (Tab. 1 e 2). Apenas em uma fêmea nulípara o valor da espessura uterina total foi semelhante ao encontrado nas não nulíparas. 
Em outra fêmea não nulípara, a espessura uterina total foi menor que a observada para a maioria das nulíparas. A média da espessura da camada mucosa do útero das fêmeas não nulíparas foi maior que a das nulíparas, entretanto os valores são discrepantes nas duas categorias de fêmeas.

Levando-se em consideração que altas doses de hormônios foliculares podem alterar a morfologia uterina (Zondek, 1936), que a mucosa uterina modifica-se em relação ao ciclo reprodutivo da fêmea (Banks, 1992; König e Liebich, 2004) e que, na paca, o útero da fêmea jovem possui camada muscular mais delgada (Matamoros, 1981), seria necessária, além da realização da mensuração, uma análise mais detalhada das condições de cada fêmea quanto ao ciclo reprodutivo e às possíveis ocorrências de disfunções no sistema reprodutor, correlacionando todos esses dados para se conseguir resultados mais conclusivos.

Tabela 1. Valores (em $\mu \mathrm{M}$ ) das medidas da espessura total e da espessura da camada mucosa do útero e relação entre essas duas medidas (\%) em cutias adultas não nulíparas

\begin{tabular}{cccc} 
Animal & $\begin{array}{c}\text { Espessura total do } \\
\text { útero }(\mu \mathrm{M})\end{array}$ & $\begin{array}{c}\text { Espessura da camada } \\
\text { mucosa do útero }(\mu \mathrm{M})\end{array}$ & $\begin{array}{c}\text { Relação entre } \\
\text { espessura da camada } \\
\text { mucosa e espessura } \\
\text { total do útero }(\%)\end{array}$ \\
\hline 2 & 1033,30 & 416,44 & 40,30 \\
3 & 682,06 & 213,73 & 31,33 \\
5 & 2285,29 & 1253,25 & 54,84 \\
7 & 1636,61 & 689,24 & 42,11 \\
Média & 1409,31 & 643,16 & 42,22 \\
\hline
\end{tabular}

Tabela 2. Valores (em $\mu \mathrm{M}$ ) das medidas da espessura total e da espessura da camada mucosa do útero e relação entre essas duas medidas (\%) em cutias adultas nulíparas

\begin{tabular}{cccc} 
Animal & $\begin{array}{c}\text { Espessura total do } \\
\text { útero }(\mu \mathrm{M})\end{array}$ & $\begin{array}{c}\text { Espessura da camada } \\
\text { mucosa do útero }(\mu \mathrm{M})\end{array}$ & $\begin{array}{c}\text { Relação entre a } \\
\text { espessura da camada } \\
\text { mucosa e a espessura } \\
\text { total do útero }(\%)\end{array}$ \\
\hline 1 & 555,12 & 282,06 & 50,81 \\
4 & 976,32 & 415,69 & 42,57 \\
8 & 1072,60 & 322,63 & 30,07 \\
6 & 836,13 & 389,38 & 46,57 \\
Média & 860,04 & 352,44 & 42,505 \\
\hline
\end{tabular}

\section{CONCLUSÕES}

O útero da cutia apresenta topografia similar ao das espécies domésticas e ao dos roedores, e é classificado com o duplo parcial. A espessura de sua camada mucosa é maior nas fêmeas não nulíparas do que nas nulíparas, embora os valores, sejam discrepantes em ambas.

\section{REFERÊNCIAS BIBLIOGRÁFICAS}

ARAUJO, W.R.; CARVALHO, M.A.M.; MOURA, S.G. et al. Parâmetros macroscópicos e biométricos dos órgãos genitais femininos de cutias (Dasyprocta agouti). Rev. Bras. Reprod. Anim., v.5, p.178-180, 2002.
BANKS, W.J. Histologia veterinária aplicada. 2.ed. São Paulo: Manole, 1992. 629p.

BESSELSEN, D.G., Biology of laboratory rodents. 2003. Disponível em: $<$ http://www.ahc.arizona.edu/uac/notes/classes/r odentbio/rodentbio.html $>$. Acessado em: $15 \mathrm{fev}$. 2005.

CHAVES, J.W.N.; SANTOS, J.H.R. Cutia. 2005. Disponível em: <http://www.esam.br/zoobotanico/animais/cutia. htm>. Acessado em: 21 jan. 2008.

COOPER, G.; SCHILLER, A.L. Anatomy of the guinea pig. Cambridge: Harvard University, 1975. 328p. 
DELLMAN, H.D.; BROWN, E.M. Histologia veterinária. Rio de Janeiro: Guanabara Koogan, 1982. 307p.

DYCE, K.M.; SACK, W.O.; WENSING, C.J.G. Tratado de anatomia veterinária. 3.ed. Rio de Janeiro: Guanabara Koogan, 2004. p.164-207.

FELIPE, A.; CALLEJAS, S.; CABODEVILA, J. Anatomicohistological characteristics of female genital tubular organs of the South American nutria (Myocastor coypus). Anat. Histol. Embryol., v.27, p.245-250, 1998.

GARTNER, L.P.; HIATT, J.L. Tratado de histologia. Rio de Janeiro: Guanabara Koogan, 1999. p.365-368.

GRAY, C.A.; BARTOL, F.F.; TARLETON, B.J. et al. Desenvolvimento biológico de glândulas uterinas. Biol. Reprod., v.65, p.1314, 2001.

GREENE, E.C. Anatomy of the rat. Philadelphia: American Philosophical Society, 1955. 92p.

GUIMARÃES, D.A. Algumas características reprodutivas da cutia fêmea (Dasyprocta prymnolopha) criada em cativeiro. 1993. 89f. Dissertação (Mestrado em Biologia) Universidade Federal do Pará e Museu Paraense Emílio Goeldi, Belém, PA.

JUNQUEIRA, L.C.; CARNEIRO, J. Histologia básica. 11.ed. Rio de Janeiro: Guanabara Koogan, 2008. 542p.

KÖNIG, H.E.; LIEBICH, H.G. Anatomia dos animais domésticos. 2.ed. São Paulo: Artmed, 2004. p.141-143.

LANGE, R.R.; SCHMIDT, E.M. S. Tratado de animais selvagens. São Paulo: Roca, 2007. 476p.

MATAMOROS, Y. Anatomia e histologia dei sistema reproductor dei tepezcuinte (Cunicullus paca). Rev. Biol. Trop., v.29, p.155-164, 1981.
MAYOR, P.; LÓPEZ-BÉJAR, M.; JORI, F. et al. Anatomicohistological characteristics of the genital tubular organs of the female brush-tailed porcupine (Atherurus africanus, Gray 1842) from Gabon. Anat. Histol. Embryol., v.31, p.355361, 2002.

MAYOR, P.; JORI, F.; LÓPEZ-BÉJAR, M. Anatomicohistological characteristics of the tubular genital organs of the female Collared Peccary (Tayassu tajacu) from north -eastern Amazon. Anat. Histol. Embryol., v.33, p.65-74, 2004.

MOURA, S.G.; CARVALHO, M.A.M.; ARAÚJO,W.R. et al. Proposta de classificação para útero da cutia (Dasyprocta aguti, Linnaes, 1766). Rev. Bras. Reprod. Anim., v.27, p.284285, 2003.

NICKEL, R.; SCHUMMER, A.; SEIFERLE, E. The viscera of the domestic mammals. 2.ed. Berlim: Verlag Paul Parey, 1979. p.351-389.

OJASTI, J. Estudio biológico del chiguire o capibara. Caracas: Fondo Nacional de Investigaciones Agropecuarias, 1973. p.262.

PRAAG, E.V. Reproductive tract of the female rabbit. 2003. Disponível em: <http://www.MediRabbit.com/urogenital tract of rabbits>. Acessado em: 16 fev. 2005.

SCHWARZE, E.; SCHRÖDER, L. Compendio de anatomia veterinária: sistema visceral. 2.ed. Zaragoza: Acribia, 1970. p.277-286.

SMALLWOOD, J.E. A guided tour of veterinary anatomy. Philadelphia, W. B Saunders, 1992. p.340-365.

ZONDEK, B. The effect of prolonged application of large doses of follicular hormone on the uterus of rabbits. 1936. Disponível em: <http://www.jem.org>. Acessado em: 28 abr. 2008. 